\title{
Ethical Dilemmas in Posthumous Assisted Reproduction
}

\author{
Iliadis $\mathrm{Ch}^{1}$, Frantzana $\mathrm{A}^{2 *}$, Ouzounakis $\mathrm{P}^{3}$ and Tachtsoglou $\mathrm{K}^{4}$ \\ ${ }^{1}$ Private Health Center, Greece \\ ${ }^{2}$ Department of Health Sciences, European University of Cyprus, Greece \\ ${ }^{3}$ General Hospital of Alexandroupoli, Greece \\ ${ }^{4}$ General Hospital of Thessaloniki "G Gennimatas", Greece
}

*Corresponding author: Aikaterini Frantzana, Department of Health Sciences, European University of Cyprus, Greece.

To Cite This Article: Frantzana A. Ethical Dilemmas in Posthumous Assisted Reproduction. Am J Biomed Sci \& Res. 2019 - 5(3). AJBSR.MS.ID.000902. DOI: 10.34297/AJBSR.2019.05.000902.

Received: 眥July 22, 2019; Published: 眥 September 17, 2019

\begin{abstract}
Introduction: Posthumous assisted reproduction is a method that is being used by more and more people to acquire children. Men donate their genetic material while in life or just before they die, so they can continue their genealogy.

Purpose: The purpose of this review is to present ethical dilemmas in posthumous artificial fertilization.

Methodology: The material of the study has been recent articles on the subject. They have been mainly found through the electronic database Medline and the Hellenic Academic Libraries Link (HEAL-Link), with the following keywords: ethical dilemmas, artificial fertilization, and posthumous assisted reproduction.

Results: Posthumous assisted reproduction now appears as a given reality. Many reservations have been raised regarding the permissibility of posthumous artificial fertilization. The most important thing is that the child born after posthumous artificial fertilization will not have a father. The institution of posthumous assisted reproduction is appropriate only for couples, married or unmarried, and not for single solitary women. The child to be born will be considered as a child born into a marriage while the partner's spouse's paternity whose consent to heterologous fertilization had been given, will not be affected.
\end{abstract}

Conclusions: The need for a single legal framework to be applied by all countries is necessary, since to date, each state has established its own laws and rules to deal with issues arising from assisted reproduction.

\section{Introduction}

The rapid development of biochemistry, genetics and biotechnology, not only the great technological advances but also the modern methods of the medical sciences on, address problems such as low fertility and infertility, disconnecting sexual intercourse from reproduction, thus, giving hope to thousands of people to have descendants, a possibility that nature deprived them of [1]. According to surveys, about 12,000 medically assisted reproduction efforts are performed in Greece and of which $40 \%$ are successful. Therefore, children are estimated at around 4,800. These figures justify the enormous effort of the legislator to delineate the operation of centers of medically assisted reproduction and secure this new form of family formation [2]. As methods of assisted reproduction or artificial insemination are defined all the possible ways of acquiring children with artificial medical methods, which have been discovered and those that will be discovered in the future [3].
According to Medical Science, those methods are [3]:

a) Artificial insemination: This is a special but simple procedure in which processed and prepared semen is placed in the woman's womb.

b) In vitro fertilization (IVF): It is a process that involves the fertilization of the ovum in the laboratory, outside the woman's body.

c) Micro fertility (ICSI): During this procedure, the doctor inserts a sperm into the ovum using a micro needle in the lab.

d) Surrogate motherhood: In this process a woman undertakes to become pregnant and carry the human embryo for a couple who cannot have children because the woman is not able to be pregnant.

e) Postmortem reproduction: This practice consists of 
preserving the gametes or embryos (after the IVF process) and the afterwards transferring them to the uterus after the donor's death. For this reason, it is also called homologous posthumous artificial fertilization.

In vitro fertilization is again distinguished in [4]:

a) Artificial sperm fertilization by a donor.

b) Artificial insemination with a surrogate mother. This procedure is further distinguished in full and partial substitution.

Simultaneously, Legal Science is based on the constitution rather than on medical methods. Therefore, it can be distinguished in [5]:

a) Authorized and unauthorized fertilization

b) In-life and posthumous fertilization

c) Fertilization of spouses and fertilization of an unmarried woman

d) Homologous and heterologous fertilization.

However, methods of medically assisted reproduction raise both moral and legal issues, even though nowadays, a large proportion of the population owes its existence to some of them $[4,6]$. The purpose of this review is to highlight and delve into problems that arise and must be addressed in the case of posthumous artificial insemination. As far as the methodology is concerned, a literature review was carried out concerning topic-related articles and books of the last two decades via electronic databases such as PubMed, Google Scholar and Scopus with keywords: Ethical dilemmas, treatment, artificial fertilization and posthumous artificial fertilization.

\section{Talking About the Posthumous Assisted Reproduction}

Posthumous assisted reproduction, according to Greek legislators, is formed using cryopreserved germ material (semen or fertilized ovum) after the death of the husband or the women's partner. This genetic material is then applied to both posthumous assisted reproduction and posthumous fertilization of the fertilized ovum to the woman's body [7]. According to Law $3089 / 2002$, posthumous assisted reproduction must be carried out three hundred days after the death of the husband-partner in order to establish a presumption of marriage origin and establish relationship [8].

In accordance with Article 1457 of the Civil Code, posthumous assisted reproduction is permitted after the death of the husband or the woman's permanent partner following a legal permit, only if the following conditions are cumulatively fulfilled:

a) The husband or the woman's partner suffered from a condition associated with the potential risk of infertility or the risk of death

b) The husband or the woman's partner has consented to a notarial deed in posthumous assisted reproduction.

In other words, it is prerequisite that the spouse or partner have had specifically approved for posthumous insemination, in the form of a notarial deed. The law allows the deceased's spouse or partner to decide within a period of six (6) months whether she is subjected to the proceedings, while the time limit is two years after the death of the wife's husband or the woman's partner. The reason for time limitation is related to the need to decide the issue of posthumous assisted reproduction in a short period of time so that the inheritance rights of the other relatives of the deceased or partner will not be long-lasting $[9,10]$. The institution of posthumous assisted reproduction, moreover, affects only couples, married or unmarried, and no single solitary women. The child to be born will be considered as a child born into a marriage while the husband's - partner's paternity who had consented to heterologous fertilization will not be affected [3].

Against Posthumous assisted reproduction, it was strongly suggested that this is contrary to the child's, to be born, interest, as it is planned to be born having already lost one parent and so, he will be deprived of the right to be raised by both parents. Mother's "sympathetic intention" to keep the memory of her partner alive and the father's desire to leave descendants after his death are not enough reasons so as the birth of a preplanned orphaned child to be morally justifiable [11].

\section{Special Cases of Posthumous Assisted Reproduction}

There are some special cases of posthumous assisted reproduction such as the following [12]:

\section{Posthumous artificial fertilization (posthumous insemination) without a court permit}

This is the case where posthumous insemination had taken place without prior judicial authorization. Therefore, a court decision to establish paternity for the child is needed. At that point, the legislator makes his efforts to ensure the protection of the child's interest and his inalienable right to inherit his deceased father, even if the law prerogative had not been respected. After all, every child regardless of his conception must inherit his father. Still, even if the posthumous fertilization is made after the end of the two-year period, the solution adopted serves again the child's interests [13].

\section{Posthumous assisted reproduction using foreign genital material (heterologous)}

Heterologous posthumous fertilization refers to the case where a woman uses foreign genital material after her husband's death 
aspiring to provide the child with the presumption of the husband's paternity. Therefore, there is neither provision for the spouse's consent to notarization for heterologous posthumous insemination, nor the possibility for the court to authorize such fertilization. Therefore, in the heterologous fertilization the child to be born will be a child born out of marriage and the spouse's paternity, as non-existent, will not be even able to be proved in trial [14]. But there are also some legal scientists who believe heterologous posthumous assisted reproduction should be legitimate. According to them, the prevailing view that the law opposed to heterologous artificial posthumous fertilization does not find a safe basis on the letter of law. The right to posthumous artificial fertilization and therefore, since the law does not exclude it, heterologous artificial posthumous fertilization is enshrined in Article $5 \S 1$ S. It is not admissible only when it conflicts with the rights of others or when it is based on morality [15]. Finally, there is also the intermediate view that no catholic attitude towards heterologous posthumous assisted reproduction is adopted. Thus, heterologous post-mortem fertilization is permitted, but heterologous posthumous assisted reproduction is prohibited in the strict sense of the term [14].

\section{Posthumous assisted reproduction and premature birth}

According to Law 3089/2002, posthumous assisted reproduction should be carried out three hundred days after the death of the spouse in order to establish a presumption of marriage origin and to establish relationship. What happens, however, in the rare case that a child is born, despite posthumous fertilization, within three hundred days of the husband's death? Undoubtedly, the protection of the child's best interests outweighs the purpose of preserving the limits of lawfulness. Moreover, the scarcity of the above case minimizes the risk of the limits being exceeded. The spirit of the law, therefore, does not require the removal a favorable regulation of a premature born child for this. Let's not forget that Law 3089/2002 has been characterized as "child-centered" by many individuals [16].

\section{Posthumous implantation of a fertilized ovum}

Posthumous implantation of a fertilized ovum collects higher levels of social consensus than posthumous fertilization. In this case, IVF semen fertilization had already taken place before the death of the husband. So, only after the husband's death, implantation of the fertilized ovum into the womb of the woman occurs [17]. The most common example of posthumous implantation that concerns jurisprudence refers to the case where several ova have been fertilized or cryopreserved. The first implantation attempts fail, and in the meantime, the death of the husband happens. So, the woman asks the bank for fertilized ova to resume the process. The woman is at this stage closer to childbirth than in the case of posthumous fertilization. So, rejection in the given process seems harder [18]. All the above apply, according to Law 3089/2005, and, also in the case where there was not any marriage with the deceased's permanent relation.

\section{Posthumous assisted reproduction with proportional application of AK 1457 and A.K. 1458 for the deceased woman}

Law 3089/2002 explicitly establishes the right to posthumous fertilization of a widow, but the Law does not regulate the corresponding right of posthumous assisted reproduction of the surviving husband and the risk of death of the wife/of a former spouse/partner. The law omitting that case is covered by the proportional application of AKs. 1457 and AK 1485. As it is reasonable in this case, the assistance of a pregnant woman (surrogate motherhood) will be needed $[18,19]$.

\section{Ethical Problems Regarding Posthumous Artificial Fertilization}

Posthumous assisted reproduction now appears as a given reality, which, as we have seen, has been legislated in our country, despite any objections - reservations (religious, philosophical, ethical, and metaphysical). There have been many objections to the permitted posthumous fertilization. The most important thing is that a child born with under the technique of posthumous assisted reproduction will not have a father. In this view, a child will be born "on demand", orphaned by a father [20]. Nevertheless, this method affects the child's interests, as it is claimed that the child will not be able to be raised by both parents. Posthumous assisted reproduction is certainly controversial because it is a marginal, if not an extreme case [21-26]. If the child's basic rights (upbringing, living) cannot be guaranteed, it cannot be judged to be an advantageous solution for the child himself or his non-conception. Moreover, as it has already been mentioned, a possible ban would be fatal for the legal status of the illegitimate child born [21].

Besides, it is preferable to be controllable posthumous assisted reproduction as regards its conditions and consequences, rather than equivalent doubts concerning the regulations and adverse consequences for the child [5]. The fundamental right under the umbrella of the law is the right to life. The right to death is not formed. Moreover, rights-holders can only be living people in accordance with the rule of Law. Therefore, we cannot refer either to the interest of the unborn child or to the interest of the deceased parent [8]. About the sperm donor, one of his fundamental rights is the right to determine the time and the mode of use of the semen. This right is an aspect of the right of the individual towards reproduction, but it is also of the most general right of the man to define himself as his personality. But is it morally, legally and socially acceptable that the donor can determine the posthumously use of his semen? [4].

On the other hand, the birth of a child presupposes the free will and constant vigilance of both parents and not the arbitrary initiative of only one parent. Therefore, the wife ought not to treat the deceased husband's genetic material as a "souvenir" [22]. Therefore, the consent of the person concerned should be given at 
the time of the artificial insemination as the data are volatile [27]. Furthermore, in the case where the interested individual wishes to withdraw his original decision, the right should be valid [23]. It is remarkable that there are cases in which the mother ignores her husband's objection by a notarial deed in the process of posthumous artificial insemination, with a view to satisfying her personal needs [20]. In addition, there seems to be suspicion concerning the potential motives and the ultimate goals that the wife may have. Some writers emphasize the self-interest that characterizes the will of the wife to move on to this method, with a major incentive to inherit her husband's/partner's property. It is indeed very sad and morally unacceptable a child to be born for utilitarian reasons. In the case where the mother carries out a posthumous conception, her share of property as a beneficiary falls to $1 / 4$, but the remaining relatives are totally excluded from the heritage [21].

It is also argued that posthumous fertilization is contrary to morality the Greek common beliefs which are surely influenced by Christian teaching. The Church considers that the child's birth by a dead parent is contrary to nature and it is therefore considered abominable [8]. Therefore, according to the prevailing moral perception, the conception and birth of a child is only acceptable if it results from living persons. Otherwise, traditional family unity is abolished, and nature is at risk of being substituted by the achievements of modern technology [22]. People through the reproductive process create achievements of modern technology [22]. People create not only an extension of themselves but of humankind through the reproductive process. This is evident above all from the preservation of the family name, but also from the relationship between the desire for childbirth and the desire for a form of immortality. This promise of immortality is further exacerbated by religion, ensuring that parental genetic material is transferred to the next generation through reproduction [21].

It should also be borne in mind that an orphaned child is born on account of the family planning of his parents. In this way, it is doubtful that a family can be preserved, with a father who will no longer exist [5]. Our social culture sets limits regarding good morals. The Greek Constitution explicitly defines the duties and obligations of both parents as well as their responsibility for the proper upbringing and education of their child. But these constitutionally defined rights of the child are violated in the case of posthumous artificial insemination [22]. The deceased husband cannot assume his role as a father, so the mother's share is the sole responsibility. This forced non-commitment, due to the absence of the father, is predetermined and contravenes the constitutional rights of the child [28]. However, the Inheritance Law primarily ensures the protection of the family in the regulation of property issues and rights. But this does not mean that law should prevent the hypothetical expansion of the family in order to protect the existing family members' expectations about property [8]. With the same reasoning, adoption should be banned if it is done by only one person, and, also every other institution; for example, fostering a child in the absence of the child's biological parents. Apart from the existence of parents, it is equally important to ensure the child's social and emotional development [7].

\section{Conclusion}

As we can see, moral dilemmas about the conception and birth of a child over the years vary and newer issues are added [23]. In other words, modern societies are concerned not only with abortions, as in antiquity, but also with modern problems such as artificial fertilization and posthumous fertilization [24,25]. Let's not forget that the protection of the child's interest as an ideal outweighs the purpose of preserving the limits of the law's permissible. This regulation of the legislator is based on both the foundation of paternity with the deceased and the safeguarding of the legal status of the child.

This is in full harmony with the child-centered spirit of the law. It is therefore understood that regardless of the permissible method and the appropriate conditions, the child needs full legal protection from the law. The need for a single legal framework to be applied by all states is considered necessary while each state has so far adopted its own laws and rules to deal with issues arising from assisted reproduction. In any case, this legal framework should be enacted and implemented with a view to the child's wellbeing who will come to the world through some of the assisted reproduction methods. Moreover, it is the establishment of a single legal framework which will determine the limits of the intervention of scientists to human nature and will enable them to refuse any act contrary to the specific legal framework.

\section{References}

1. G Moutoula (1991) Artificial Fertilization-The Developments in Genetics as an Approach to the Modernization of Family Law. Nomikos Vima 39: 994-999.

2. Huff Post's extensive research on in Vitro fertilization in Greece.

3. In vitro fertilization: All assisted reproduction methods.

4. Iatrakis GM, Anastasiadou E, Antoniou E (2009) Counseling in assisted reproduction. Publications Desmos, Greece.

5. Kourkouta L, Prokopiou E, Kleisaris Ch (2017) In vitro fertilization and moral concerns. $44^{\text {th }}$ Panhellenic Nursing Congress of ESNE, Naxos p. 10 13.

6. Kontogianni GE, Nikolaidis KP (2003) Medical Genetics. Lolos Publishing Sp Evangelica, Greece.

7. Karasi M (2002) The draft law on Medical Assistance in Human Reproduction. Critical Consideration, ChrID pp. 577.

8. Papadopoulos Klamari Dimitra (2002) Voluntary recognition of non-married children in assisted reproduction under Law 3089/2002. Criteria 2: 151-163.

9. Kounogeri Manoledaki E (2002) The Draft Law on Medical Assistance to Human Reproduction and the Counter-Reaction against It. ChrID pp. 676-679.

10. Kalokerinou EM (2002) Experimenting on human embryos: a philosophical view. Science and Society: Review of Political and Ethical Theory 8: $27-43$. 
11. Dragona Monachou M (2002) Ethical and bioethical. Science and Society: Review of Political and Ethical Theory. 8: 1-26.

12. Kourkouta Lambrini, Dokoutsidou Eleni, Papaemmanouil (2019) Love Immortal artificial fertilization. $46^{\text {th }}$ Panhellenic Nursing Congress of ESNE, Milos p. 8-11.

13. Koumoutzis Nikos (2005) Posthumous assisted reproduction using foreign genital material. ChrID pp. 668-670.

14. Kounougeri Manoledaki (2006) Posthumous assisted reproductionand premature birth: The establishment of kinship. ChRID 2005, 97-99=Birthday Apostolos S Georgiadis, Ant N Sakkoulas, Athens Komotini 1: 431-439.

15. Papachristou Athanasios (2002) Problems of inheritance law from the applications of genetic technology, in a COMPANY OF JUDICIAL STUDIES, Contributions III-Legal Approximation of the Modern Problems of Biogenetics, Ant N Sakkoulas, Athens Komotini pp. 79-85.

16. Koumoutzis Nikos (2003) Observations in Law 3089/2002. ChrID pp. 190-192.

17. Koutselinis A, Michalodimitrakakis M (1980) Thoughts and Newer Opinions on Artificial Fertilization. Pen pp. 305-312.

18. Koutsoubinas Stefanos (1994) Constitutionally Prepared in a Bioethica Issue. DIKIK pp. 1089-1096.

19. Successful Reproduction and Potential Dosage.
20. Dragona Monachou M (2002) Ethical and bioethical. Science and Society: Review of Political and Ethical Theory. 8: 1-26.

21. Bitziou SM (2018) Medical Assisted Reproduction-Legal, Economic and Ethical Issues.

22. Karpathiou S (2006) The History of Zygote and In Vitro Fertilization: Contribution to Ethical Theology.

23. L Kourkouta, P Ouzounakis, K Prodrommidis, K Koukourikos (2019) The practice of the extermination in Ancient Greece. $45^{\text {th }}$ Annual Panhellenic Medical Congress. Greece p. 15-18.

24. Kourkouta Lambrini Plati Panagiota, Karyoti Aikaterini (2019) Birth limitation measures in Ancient Greece. $46^{\text {th }}$ Panhellenic Nursing Congress of ESNE, Greece p. 8-11.

25. Kourkouta L, Lavdaniti M, Zyga S (2013) Views of ancient people on abortion. Health Science Journal (7): 116-118.

26. Nakhuda GS (2010) Posthumous assisted reproduction. Semin Peprod Med 28(4): 329-335.

27. Efrat Ram Tiktin, Roy Gilbar, Ronit B Fruchter, Ido Ben Ami, Shevach Friedler, et al. (2018) Expanding the use of posthumous assisted reproduction technique: Should the deceased's parents be allowed to use his sperm? Clinical Ethics 14(1): 18-25.

28. Kopeika J, Thornhill A, Khalaf Y (2015) The effect of cryopreservation on the genome of gametes and embryos: principles of cryobiology and critical appraisal of the evidence. Hum Reprod Update 21(2): 209-227. 